ARTICLE

https://doi.org/10.1038/s41467-020-15314-9

\title{
Electricity-powered artificial root nodule
}

\author{
Shengtao Lu (1) ${ }^{1}$, Xun Guan (1) ${ }^{1} \&$ Chong Liu (1) ${ }^{1,2}{ }^{凶}$
}

Root nodules are agricultural-important symbiotic plant-microbe composites in which microorganisms receive energy from plants and reduce dinitrogen $\left(\mathrm{N}_{2}\right)$ into fertilizers. Mimicking root nodules using artificial devices can enable renewable energy-driven fertilizer production. This task is challenging due to the necessity of a microscopic dioxygen $\left(\mathrm{O}_{2}\right)$ concentration gradient, which reconciles anaerobic $\mathrm{N}_{2}$ fixation with $\mathrm{O}_{2}$-rich atmosphere. Here we report our designed electricity-powered biological|inorganic hybrid system that possesses the function of root nodules. We construct silicon-based microwire array electrodes and replicate the $\mathrm{O}_{2}$ gradient of root nodules in the array. The wire array compatibly accommodates $\mathrm{N}_{2}$-fixing symbiotic bacteria, which receive energy and reducing equivalents from inorganic catalysts on microwires, and fix $\mathrm{N}_{2}$ in the air into biomass and free ammonia. A $\mathrm{N}_{2}$ reduction rate up to $6.5 \mathrm{mg} \mathrm{N}_{2}$ per gram dry biomass per hour is observed in the device, about two orders of magnitude higher than the natural counterparts.

\footnotetext{
${ }^{1}$ Department of Chemistry and Biochemistry, University of California, Los Angeles, Los Angeles, CA 90095, USA. ${ }^{2}$ California NanoSystems Institute (CNSI), University of California, Los Angeles, Los Angeles, CA 90095, USA. ${ }^{凶}$ email: chongliu@chem.ucla.edu
} 
A major component of global dinitrogen $\left(\mathrm{N}_{2}\right)$ fixation occurs in root nodules ${ }^{1}$, the symbiotic plant-microbe composites in which microorganisms receive energy from plants and reduce $\mathrm{N}_{2}$ into fertilizers ${ }^{2-4}$. The significance of biological root nodules in agriculture inspires us to consider a manmade mimic, which houses diazotrophs ${ }^{5,6}$ and fixes $\mathrm{N}_{2}$ in air with renewable energy such as solar electricity. Biological|inorganic hybrid systems are reported to use sustainable energy, such as light and renewable electricity to drive biochemical reactions with high throughput and energy efficiency ${ }^{7-11}$. We recently reported a biocompatible system ${ }^{7}$ that utilizes electricity to power the $\mathrm{N}_{2}$ fixation in Xanthobacter autotrophicus ${ }^{12}$, a non-symbiotic rootassociative diazotroph ${ }^{13}$. In this system, water is split into $\mathrm{O}_{2}$ and $\mathrm{H}_{2}$ with small thermodynamic driving forces ${ }^{12}$. The generated $\mathrm{H}_{2}$ as a reducing equivalent is selectively consumed by the hydrogenases in autotrophic microorganisms and powers the biochemical reduction of carbon dioxide $\left(\mathrm{CO}_{2}\right)$ and $\mathrm{N}_{2}{ }^{12}$. However, this hybrid system operates at a microaerobic condition of $2 \% \mathrm{O}_{2}$ other than ambient air, which limits its potential for practical applications. In root nodules, the anaerobic nature of $\mathrm{N}_{2}$-fixing nitrogenases is incompatible with the aerobic metabolism in plant cells ${ }^{14,15}$. In order to accommodate this incompatibility for a successful $\mathrm{N}_{2}$ reduction in air, the $\mathrm{O}_{2}$ environment in root nodules quickly changes from aerobic at the apex to hypoxic towards the base across tens or hundreds of micrometers (Fig. 1a) ${ }^{16-18}$. Such a steep $\mathrm{O}_{2}$ gradient in living organisms has been challenging to mimic with a man-made device ${ }^{19}$. Designs of hydrogel and microfluidic systems have been employed to create steady-state concentration profiles, yet these delicate setups require a continuous gas purging or supply of $\mathrm{O}_{2}$ scavengers, which are not readily tunable or attainable with long-term stability ${ }^{19-21}$. While biofilms hosting diazotrophs have been recently reported to exhibit $\mathrm{N}_{2}$ fixation in $\mathrm{air}^{22}$, their complex and less-well-defined nature renders certain challenges (Supplementary Note 1).

Here we report our strategy that uses microwire array electrode to create a controllable $\mathrm{O}_{2}$ gradient for the construction of an electricity-driven artificial root nodule (Fig. 1b). The wire array compatibly accommodates $\mathrm{N}_{2}$-fixing symbiotic bacteria within it and provides energy and reducing equivalents to the bacteria. Resembling the natural root nodules, the generated local hypoxic environment within the microwire array enables the biological $\mathrm{N}_{2}$-fixation in air. The reported biological|inorganic hybrid system can potentially supplement non-legume crops with electricity-generated fertilizers and reduce the reliance on synthetic alternatives.

\section{Results}

Design principle and numerical simulations. In our design, microwire array electrode provides a suitable platform of delivering reducing equivalents to biocatalysts, as well as establishing a controllable $\mathrm{O}_{2}$ environment for biological $\mathrm{N}_{2}$ fixation in air (Fig. 1b). Under a cathodic electrochemical potential, the large surface area of wire array electrode offers fast transfer of reducing equivalents to the microbes through either a direct or a mediated pathway (Fig. 1b) ${ }^{9,23}$. Moreover, in air, the electrochemical a

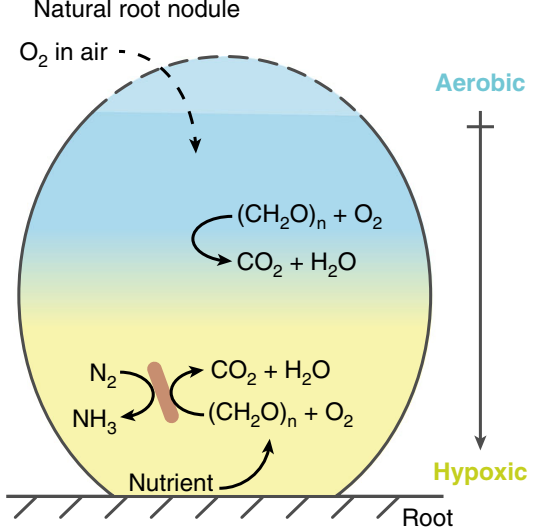

b Artificial root nodule

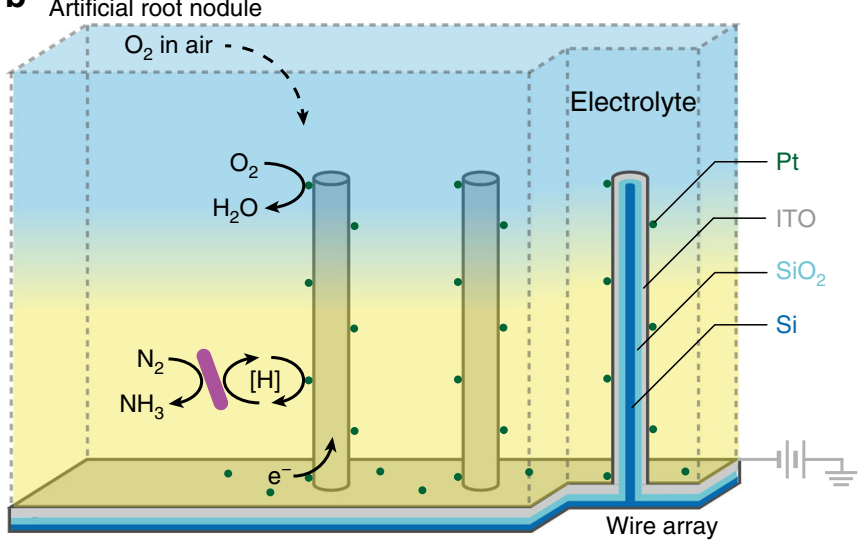

C

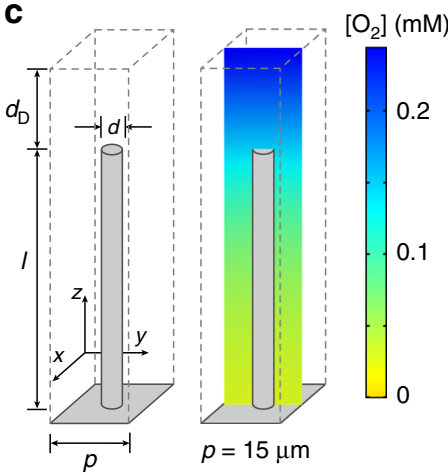

d

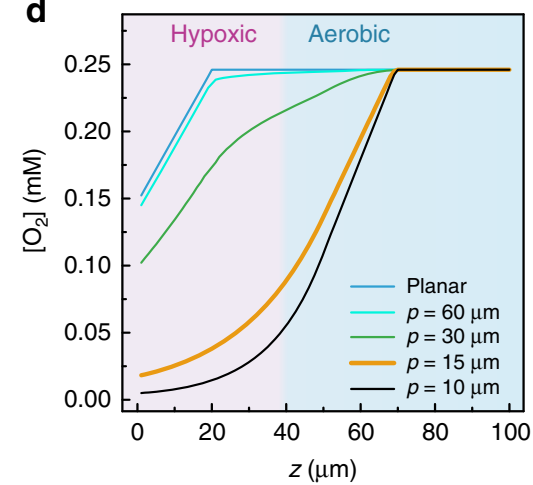

Fig. 1 Scheme and the simulated $\mathbf{O}_{\mathbf{2}}$ gradient of electricity-driven artificial root nodule. Scheme of $\mathrm{N}_{2}$ fixation in the natural a and the proposed artificial root nodule $\mathbf{b}$. c Morphology of designed microwire array and the cross-sectional display of simulated $\mathrm{O}_{2}$ concentration $\left(\left[\mathrm{O}_{2}\right]\right)$ profile. Length $(I), 50 \mu \mathrm{m}$; diameter $(d), 4 \mu \mathrm{m}$; periodicity $(p), 15 \mu \mathrm{m}$; diffusion layer thickness $\left(d_{D}\right), 20 \mu \mathrm{m}$. d Simulated $\left[\mathrm{O}_{2}\right]$ against the distance from the base of electrode $(z)$ for planar electrode and microwire arrays of different $p$ values $(I=50 \mu \mathrm{m}, d=4 \mu \mathrm{m})$. The hypoxic (pink) and aerobic (blue) domains for wire array of $p=$ $15 \mu \mathrm{m}$ are suggested. e Scanning electron microscopy (SEM) image of the prepared Si wire array with a morphology shown in c. ITO indium-tin oxide. Scale bar, $15 \mu \mathrm{m}$. Electrochemical potential $\left(E_{\text {appl }}\right)=0.5 \mathrm{~V}$ vs. reversible hydrogen electrode $(R H E)$ in $\mathbf{c}$ and $\mathbf{d}$. 
reduction of $\mathrm{O}_{2}$ on electrode's surface consumes $\mathrm{O}_{2}$ and creates a local $\mathrm{O}_{2}$ gradient in the solution. This effect is much more pronounced for porous and large-surface-area electrodes in general $^{24-27}$, effectively creating an $\mathrm{O}_{2}$-free domain within the wire array suitable for anaerobic $\mathrm{N}_{2}$ fixation (Fig. 1b). Our previous work demonstrated a $\mathrm{O}_{2}$-free domain within a nanowire array electrode 23,25 , which allows anaerobic microbial reduction of $\mathrm{CO}_{2}$ in air $^{23}$. Here we apply the same design principle for an artificial root nodule. Numerical simulations based on a microkinetic model were applied to design a suitable wire array geometry for biological $\mathrm{N}_{2}$ fixation (see "Methods" section). When the wire electrode was at an electrochemical potential $\left(E_{\text {appl }}\right)$ cathodic enough to reduce $\mathrm{O}_{2}\left(E_{\text {appl }}=0.5 \mathrm{~V}\right.$ vs. reversible hydrogen electrode, $\mathrm{RHE}$ ) at $\mathrm{pH}=7.0$ (same below), the $\mathrm{O}_{2}$ concentration near the electrode $\left(\left[\mathrm{O}_{2}\right]\right)$ quickly decreases towards the base of wire array (Fig. 1c), establishing an $\mathrm{O}_{2}$ gradient more significant than the case when a planar electrode is employed (Fig. 1d and Supplementary Fig. 1). We studied how the periodicity of wire array $(p)$ impacts the constructed $\mathrm{O}_{2}$ gradients. Larger value of $p$ leads to a gentler $\mathrm{O}_{2}$ gradient (Fig. 1d), illustrating the tunability of constructing $\mathrm{O}_{2}$ gradient with different $p$ values. At $p=15 \mu \mathrm{m}$ and wire length $l=50 \mu \mathrm{m}$ (yellow trace in Fig. 1d), a majority of the solution within the wire array is predicted to be hypoxic $\left(<5 \% \mathrm{O}_{2} \text {, pink area in Fig. } 1 \mathrm{~d}\right)^{19}$, suitable for biological $\mathrm{N}_{2}$ fixation (see Supplementary Note 2$)^{5,12}$.

Fabrication and characterization of wire array electrodes. The microwire array device, designed based on numerical simulation (Fig. 1c, d), was constructed for electricity-driven $\mathrm{N}_{2}$ fixation in air. A five-step fabrication process (see "Methods" section) led to a core-shell microwire array, which contains a silicon $(\mathrm{Si})$ microwire core, a $\mathrm{SiO}_{2}$ insulating coating, a layer of indium-tin oxide (ITO), and Pt particles deposited via sputtering (Fig. 1b) ${ }^{28}$. The electrically conductive ITO layer ensures a uniform distribution of $E_{\text {appl }}$ on wires' surface; the Pt particles not only transfer reducing equivalents to diazotrophs for $\mathrm{N}_{2}$ fixation but also electrochemically consume $\mathrm{O}_{2}$ for a controlled $\mathrm{O}_{2}$ gradient ${ }^{29,30}$. The morphology and composition of the wire array were characterized and confirmed by scanning electron microscopy (SEM) equipped with energydispersive X-ray spectroscopy (EDS) (Fig. 1e and Supplementary Fig. 2). Linear scan voltammograms (LSVs) of the array electrode in an all-inorganic medium for diazotrophs displayed an onset potential of $\mathrm{O}_{2}$ reduction at $0.8 \mathrm{~V}$ vs. RHE and a noticeable generation of $\mathrm{H}_{2}$ when $E_{\text {appl }}<0 \mathrm{~V}$ vs. RHE (Supplementary Fig. 3 and see "Methods" section), confirming the proposed functionalities of deposited Pt catalysts.

Optical quantification of $\mathrm{O}_{2}$ gradient within wire array. We experimentally validated the predicated $\mathrm{O}_{2}$ profile within the designed wire array using confocal microscopy. Tris $(1,10-$ phenanthroline) ruthenium(II) dication, $\mathrm{Ru}(\text { phen })_{3}{ }^{2+}$, was employed as a molecular $\mathrm{O}_{2}$ sensor. After optical excitation $\left(\lambda_{\mathrm{ex}}=470 \mathrm{~nm}\right)$ and a subsequent intersystem crossing (ISC), the photo-excited triplet state $\left(\mathrm{T}_{1}\right)$ of $\mathrm{Ru}(\text { phen })_{3}{ }^{2+}$ can be effectively quenched by $\mathrm{O}_{2}$ in the solution (Fig. $\left.2 \mathrm{a}\right)^{31,32}$. Thus the intensity $\left(I_{\mathrm{em}}\right)$ and lifetime $(\tau)$ of phosphorescence emission for $\mathrm{Ru}$ (phen) ${ }_{3}{ }^{2+}$ are inversely proportional to local $\left[\mathrm{O}_{2}\right]$, a relationship that allows optical mapping of $\left[\mathrm{O}_{2}\right]$ profile. We constructed an electrochemical set-up that houses the wire array in a threeelectrode configuration on a confocal microscope (see "Methods" section, Fig. $2 \mathrm{~b}$ and Supplementary Fig. 4). Under a constant flow of aerated medium solution of $0.1 \mathrm{mM} \mathrm{Ru}$ (phen) ${ }_{3}{ }^{2+}$, the spatial distribution of $I_{\mathrm{em}}$, subsequently the local $\left[\mathrm{O}_{2}\right]$ near the electrode, was characterized at different $E_{\text {appl }}$ and microwire morphologies (Fig. 2c, d and Supplementary Fig. 5). The side-views of three- dimensional $I_{\text {em }}$ mappings were displayed when $E_{\text {appl }}$ was absent ("voltage off") in Fig. $2 c$ and $E_{\text {appl }}=0.5 \mathrm{~V}$ vs. RHE ("voltage on") in Fig. 2d. The $I_{\mathrm{em}}$ profile in Fig. $2 \mathrm{~d}$, qualitatively stronger than the one in Fig. $2 c$, suggests a local $\mathrm{O}_{2}$ depletion in the wire array. Temporal control of the established $\mathrm{O}_{2}$ gradient was achieved, as the normalized values of $I_{\mathrm{em}}\left(I_{\mathrm{t}} / I_{0}\right)$ at different depths of the wire array were all responsive towards $E_{\text {appl }}$ variations (Fig. 2e). It is worth noting that Fig. 2c, d are just qualitatively illustrating the presence of $\mathrm{O}_{2}$ gradient, since the light absorption of Si microwire may interfere for a quantitative analysis of $\mathrm{O}_{2}$ concentrations based on phosphorescent intensity. In order to circumvent such an issue, we applied phosphorescence lifetime imaging microscopy (PLIM) technique to quantify the $\mathrm{O}_{2}$ gradient (Fig. 2f) after establishing a calibration curve (Supplementary Fig. 6). Figure $2 \mathrm{f}$ displayed the axial $\left[\mathrm{O}_{2}\right]$ profiles ( $z$-direction) of planar (blue points) and wire arrays with $p=15$ and $30 \mu \mathrm{m}$ (yellow and green points, respectively), along with the predicted $\left[\mathrm{O}_{2}\right]$ profiles based on numerical simulations (solid lines). The high fidelity between experimental and simulation results illustrates the viability of controlling microscopic $\mathrm{O}_{2}$ gradient by using microwire array electrode. As predicted by simulation, a hypoxic domain mimicking the zone of $\mathrm{N}_{2}$ fixation in root nodules (pink area in Fig. 2f) was fulfilled.

Electricity-driven $\mathrm{N}_{2}$ reduction with microbes in wire array. Electricity-driven $\mathrm{N}_{2}$ reduction in air was demonstrated when inoculating $\mathrm{N}_{2}$-fixing soil microorganisms into the pre-designed microwire array. $X$. autotrophicus (X. autotrophicus, ATCC $35674)^{12,13}$ and Bradyrhizobium japonicum (B. japonicum, USDA DES 122), a soybean symbiont model strain capable of oxidizing $\mathrm{H}_{2}$ as the energy source ${ }^{5,33}$, were inoculated separately into microwire array electrodes shown in Fig. 1c. In an air-equilibrated liquid medium deprived of any nitrogen and organic carbon sources (see "Methods" section), an electrochemical potential $\left(E_{\mathrm{appl}}=-0.15 \mathrm{~V}\right.$ vs. RHE) was supplied to establish the proposed $\mathrm{O}_{2}$ gradient and deliver reducing equivalents, possibly $\mathrm{H}_{2}$, for biological $\mathrm{N}_{2}$ fixation (Fig. 3a). In $120 \mathrm{~h}$ after inoculation, confocal fluorescence microscopy images (see "Methods" section) indicate significant increase of microbial population and biomass for both B. japonicum and $X$. autotrophicus strains (Fig. 3b, c and Supplementary Fig. 7). As the only possible source of nitrogen and carbon in the biomass is the $\mathrm{N}_{2}$ in the air and $\mathrm{CO}_{2}$ /bicarbonate in the medium, such a biomass increase suggests biological $\mathrm{N}_{2}$ and $\mathrm{CO}_{2}$ fixation. In contrast, when we inoculated a $B$. japonicum variant unable to fix $\mathrm{N}_{2}$ with its disrupted nifH gene (B. japonicum- $H 1)^{34,35}$, negligible biomass accumulation was observed under the same condition (Supplementary Fig. 8). This indicates that the observed biomass accumulation is concurrent with the expression of nifH protein essential to $\mathrm{N}_{2}$ reduction. Last, when there was not enough driving force $\left(E_{\text {appl }}\right)$ from electricity to drive $\mathrm{N}_{2}$ fixation, no net accumulation of biomass was observed (Supplementary Fig. 9). It supports our claim that electricity is the sole energy source of $\mathrm{N}_{2}$ fixation.

After $120 \mathrm{~h}$ since inoculation, quantitative assays (see "Methods" section) show that the changes of microbial cell counts $(\Delta C C)$ within the wire array were $4.0 \pm 1.5 \times 10^{9}$ and $4.2 \pm 1.6 \times 10^{9}$ cells $\mathrm{mL}^{-1}$ for $X$. autotrophicus and B. japonicum strains, respectively (entries 1 and 2 in Fig. $3 d$; $n=5, \pm$ denotes standard deviation, same below). The final microbial cell counts in the device are 19 and 2.5 times of the values right after the inoculation $(2.2 \pm 1.2 \times$ $10^{8}$ and $2.7 \pm 1.8 \times 10^{9}$ cells $\mathrm{mL}^{-1}$ ) for B. japonicum and $X$. autotrophicus, respectively. This highlights that the developed system is biocompatible even for symbiotic microorganisms that might demand additional stimuli for $\mathrm{N}_{2}$ fixation (Supplementary Note 3$)^{4,36}$. In correspondence to the change of cell counts, the changes of total nitrogen content $(\Delta \mathrm{TN})$ retained in biomass in the 
a

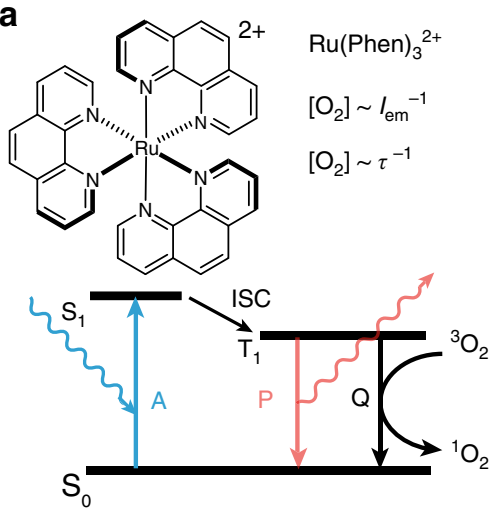

b

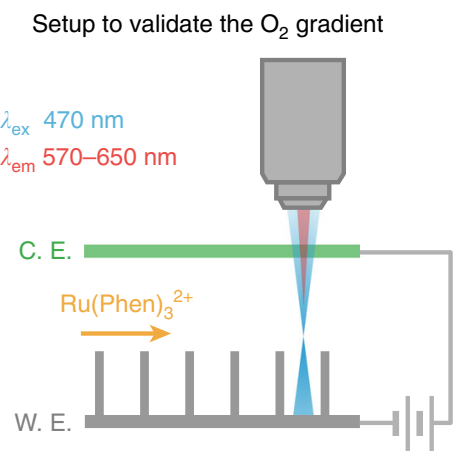

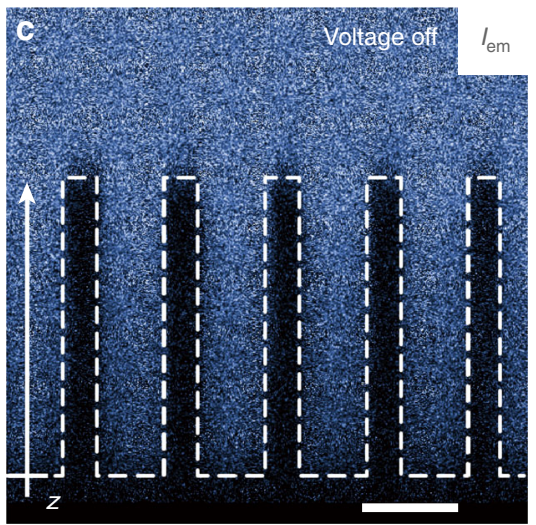

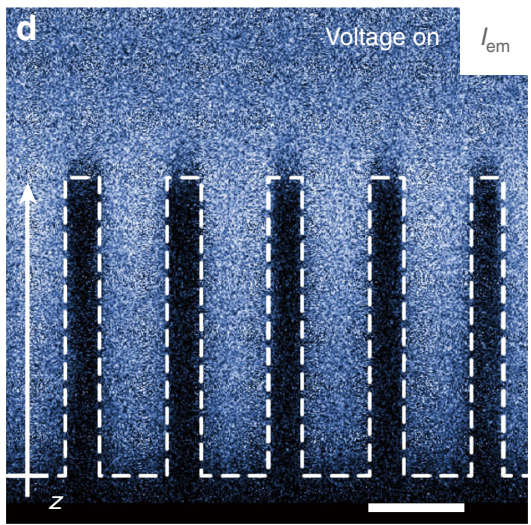

High $I_{\text {em }}$

e
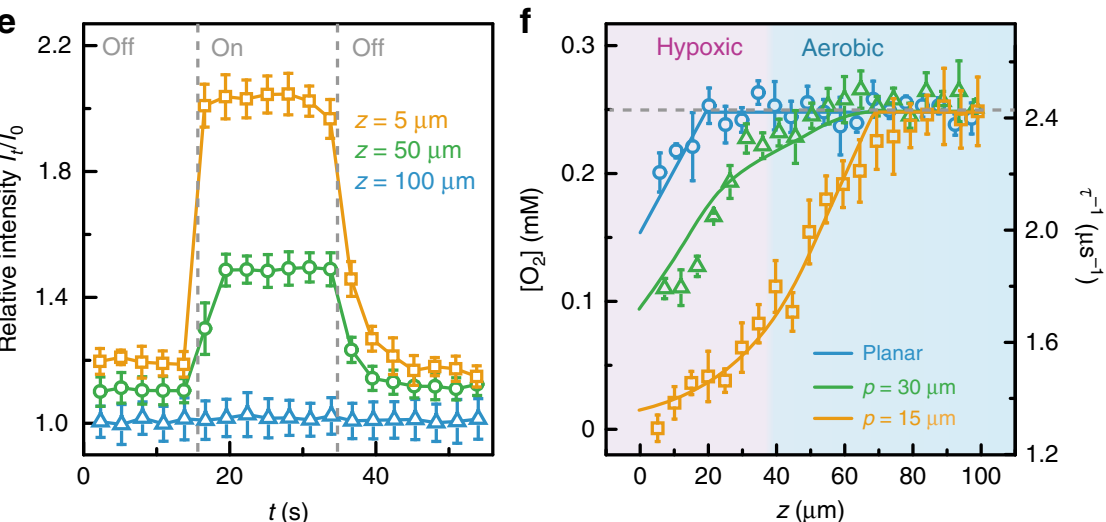

Fig. 2 Experimental validation of microscopic $\mathbf{O}_{\mathbf{2}}$ gradient in microwire array. a Simplified Jablonski diagram of Ru(phen) ${ }_{3}^{2+}$ including the absorption (A), intersystem crossing (ISC), phosphorescence (P), and the quenching (Q) of its triplet excited states by $\mathrm{O}_{2}$. l $\mathrm{l}_{\mathrm{em}}$ and $\tau$ denote the intensity and lifetime of phosphorescence emission, respectively. $\mathbf{b}$ Electrochemical setup under a confocal microscope that in situ maps $\mathrm{O}_{2}$ gradient. WE denotes microwire array working electrode and CE denotes counter electrode. The setup is mounted on an inverted microscope so the wire array is facing down during observation (as shown in Supplementary Fig. 4). c, d Cross-sectional $I_{\mathrm{em}}$ profiles in wire array in the absence and presence of $E_{\text {appl, }}$, respectively. Dashed lines depict wire morphology. Blue pseudo-colored. Scale bars, $15 \mu \mathrm{m}$. e The temporal response of relative intensities $I_{\mathrm{em}}\left(I_{t} / I_{0}\right)$ at different $z$ values within wire array. $E_{\text {appl }}$ was switched on and off at $t=15$ and $35 \mathrm{~s}$, respectively $(n=3)$. f Simulated (lines) and experimentally determined (points, $\left.n=3\right)\left[\mathrm{O}_{2}\right]$ profiles at different electrode geometries. Unless specified, all results, as well as the suggested hypoxic (pink) and aerobic (blue) areas, refer to the geometry shown in Fig. 1c under $E_{\mathrm{appl}}=0.5 \mathrm{~V}$ vs. RHE. Error bars $=$ standard deviation $(n=3)$.

device, an indicator of biological $\mathrm{N}_{2}$ fixation, were $5.7 \pm 2.3 \times 10^{2}$ and $1.9 \pm 0.7 \times 10^{2} \mathrm{mg} \mathrm{L}^{-1}$ for $X$. autotrophicus and B. japonicum strains, respectively; the changes of total organic carbon $(\Delta T O C)$, another indicator of microbial biomass accumulation, were $2.5 \pm$ $1.0 \times 10^{3}$ and $6.9 \pm 2.5 \times 10^{2} \mathrm{mg} \mathrm{L}^{-1}$ for $X$. autotrophicus and $B$. japonicum strains, respectively. Moreover, we observed the accumulation of free ammonia in the effluent out of the electricity-driven $\mathrm{N}_{2}$ fixation device. When $20 \mathrm{~mL}$ of medium was circulated throughout the device during a 120-h application of electricity, the nitrogen content in terms of ammonia in the liquid effluent was measured to increase by $0.017 \pm 0.003 \mathrm{mg} \mathrm{L}^{-1}$ for $B$. japonicum; no detectable free ammonia was observed for $X$. autotrophicus strain under the same experimental condition, consistent with our prior report with $X$. autotrophicus strains in the absence of any external inhibitor ${ }^{12}$ (see "Methods" section). This implies that under a flow condition part of the fixed ammonia is capable to passively diffuse extracellularly, resembling the scenario in the symbiotic system within a root nodule ${ }^{37}$. As far as we know, microbial-based free ammonia production from electricity has not yet been reported except our prior work that 


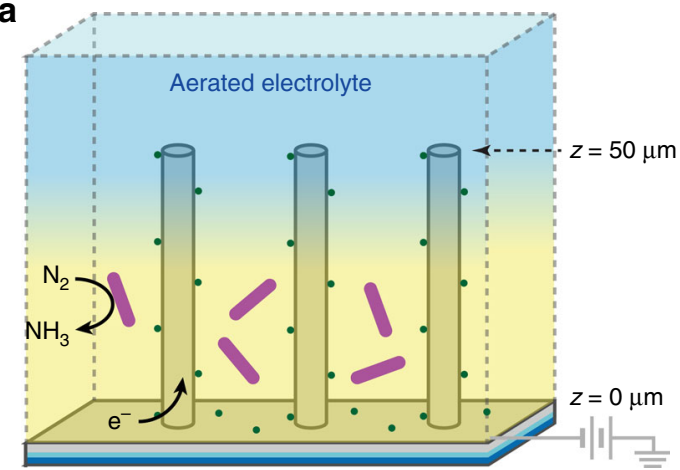

d

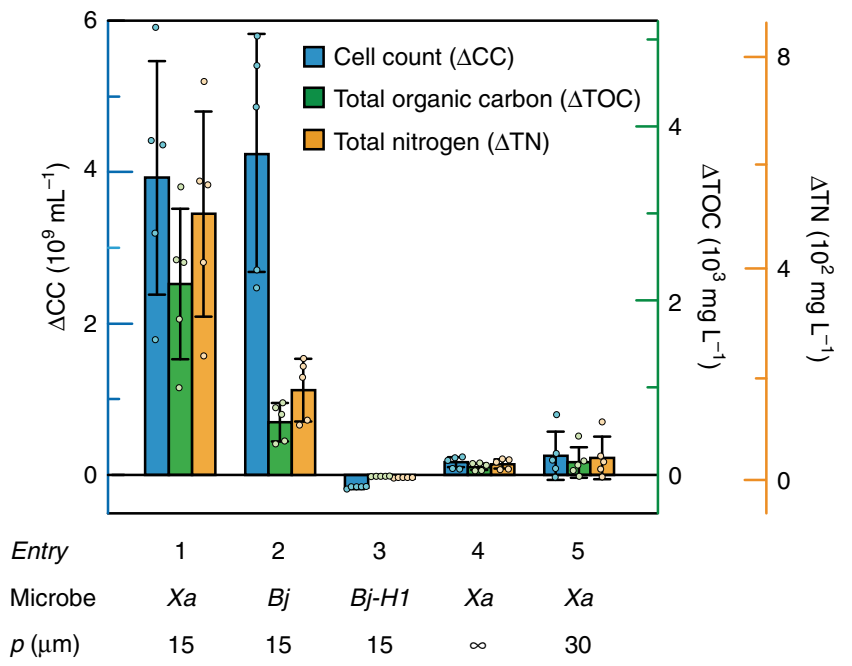

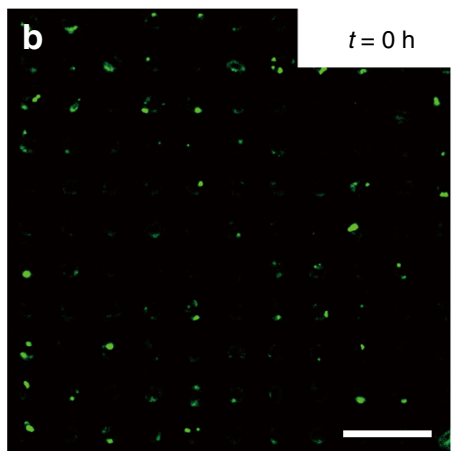

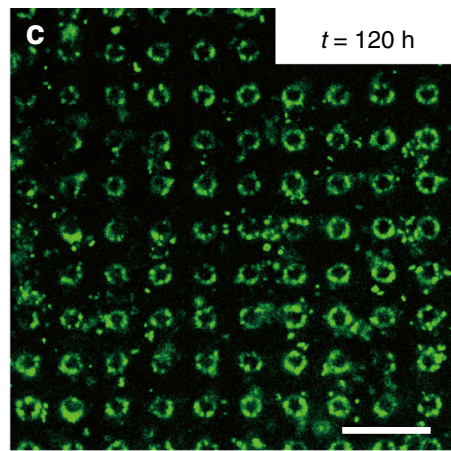

e

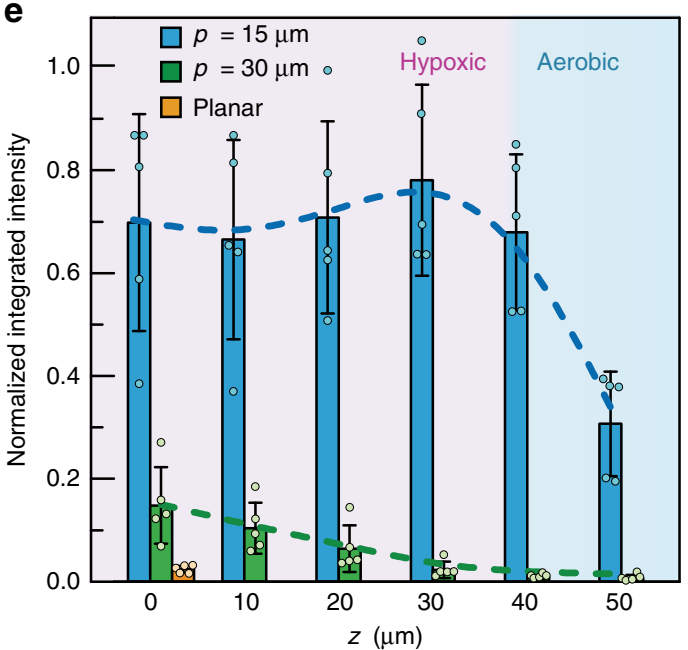

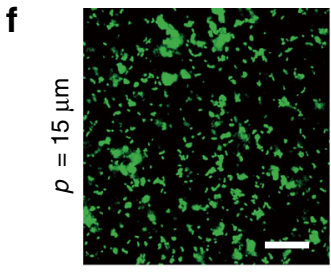

g

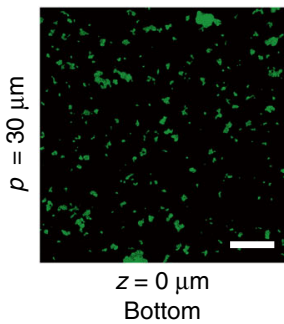

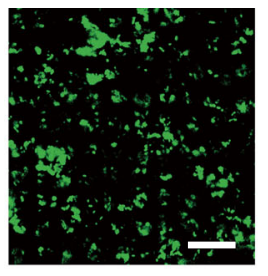
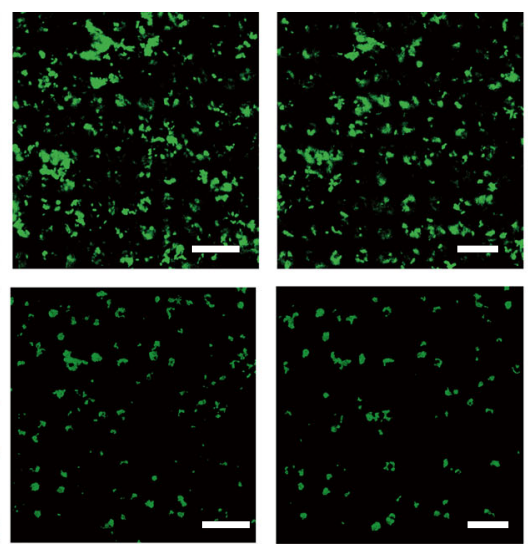

$z=10 \mu \mathrm{m}$

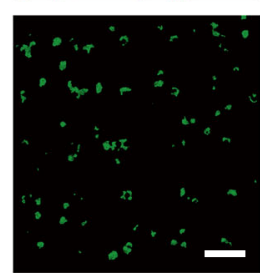

$z=20 \mu \mathrm{m}$
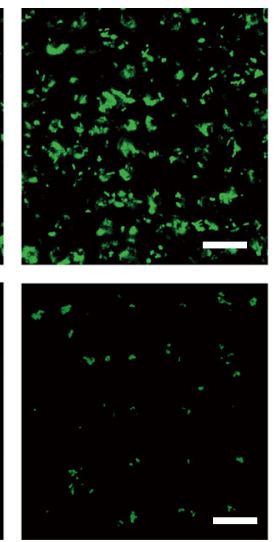

$z=30 \mu \mathrm{m}$
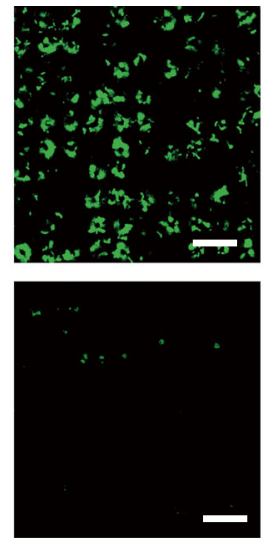

$z=40 \mu \mathrm{m}$
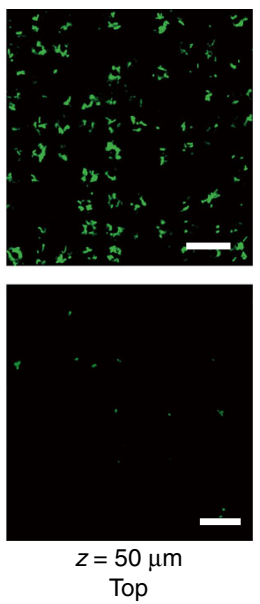

Fig. 3 Electricity-driven $\mathbf{N}_{\mathbf{2}}$ fixation in air. a Schematic illustration of the functional device. $\mathbf{b}$, $\mathbf{c}$ Fluorescent images of $B$. japonicum, indicative of biomass accumulation, before $\mathbf{b}$ and after $\mathbf{c} 120$-h operation in microwire array. $E_{\text {appl }}=-0.15 \mathrm{~V}$ vs. RHE, $p=15 \mu \mathrm{m}$, images taken at $z=20 \mu \mathrm{m}$. d Changes of cell count $(\Delta C C)$, as well as the retained total nitrogen $(\Delta T N)$ and total organic carbon $(\Delta T O C)$ in biomass in the device, calculated as the differences between values before and after 120-h operation with the provision of electricity $(n=5)$. $\infty$, planar electrode; Xa X. autotrophicus; Bj B. japonicum, Bj-H1 B. japniucum-H1, a $B$. japonicum variant with disrupted nifH gene. e Integrated fluorescent intensities of $X$. autotrophicus, indicative of biomass accumulation, at different $z$

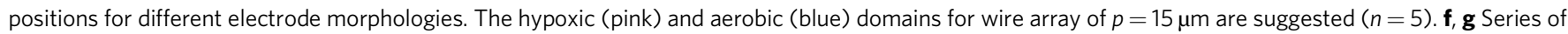
$x-y$ cross-sectional fluorescent images at different $z$ planes for $X$. autotrophicus population within wire arrays of $p=15 \mu \mathrm{m} \mathbf{f}$ and $p=30 \mu \mathrm{m} \mathbf{g}$. Pseudo-colored in green. Scale bars, $30 \mu \mathrm{m}$. The setup for imaging is mounted on an inverted microscope so the wire array is facing down during observation (as shown in Supplementary Fig. 4). For panels $\mathbf{d}$ and $\mathbf{e}$, dot-plot of individual measurements is overlaid with the bar graph. Error bars $=$ standard deviation ( $n=5$ ).

utilized inhibitor to purposely prevent microbes from up-taking ammonia $^{12}$, a non-ideal practice for long-term operation. Overall, the electricity-driven artificial root nodule is capable of fixing $\mathrm{N}_{2}$ in air at a rate of 6.5 and $1.1 \mathrm{mg} \mathrm{N} / \mathrm{g}$ dry biomass per hour for $B$. japonicum and $X$. autotrophicus strains, respectively (see "Methods" section). Such rates of $\mathrm{N}_{2}$ fixation in our system are about two orders of magnitudes higher than their natural counterparts in the symbiotic root nodules with higher energy efficiencies (see "Methods" section, Supplementary Table 1 and Supplementary Note 4$)^{4,38}$. 
$\mathrm{O}_{2}$ gradient within the wire array is crucial to $\mathrm{N}_{2}$ fixation. The established $\mathrm{O}_{2}$ gradient within the wire array is crucial to the functionality of biological $\mathrm{N}_{2}$ fixation in air. Wire array in the absence of deposited Pt particles did not lead to observable $\mathrm{N}_{2}$ fixation (Supplementary Fig. 9). It suggests that Pt particles are effective towards oxygen reduction, enable the establishment of $\mathrm{O}_{2}$ gradient, and deliver reducing equivalents to the microbes via reducing protons or possibly other direct routes of charge transfer (Supplementary Note 5). Moreover, the microbial distribution at different depths of the wire array (Fig. 3e), characterized by confocal microscopy, suggests a strong correlation between the $\mathrm{O}_{2}$ gradient and the microbial population density. When planar electrode or wire array of $p=30 \mu \mathrm{m}$ were inoculated with diazotrophs (entries 4 and 5 in Fig. $3 \mathrm{~d}$, respectively), minimal $\mathrm{N}_{2}$ fixation was observed. While the wire array of $p=15 \mu \mathrm{m}$ exhibits high microbial density until the very top $(z>40 \mu \mathrm{m}$ in Fig. 3e), which is in accordance with the $\mathrm{O}_{2}$ gradient measured under the same $E_{\text {appl }}$ for nitrogen fixation experiment (Supplementary Note 6 and Supplementary Fig. 10), planar substrate or wire array of larger $p$ value $(p=30 \mu \mathrm{m})$ did not display significant microbial accumulation. Such a difference is also visible in Fig. $3 \mathrm{f}$ ( $p=$ $15 \mu \mathrm{m})$ and Fig. $3 \mathrm{~g}(p=30 \mu \mathrm{m})$, which highlight the active diazotrophs at different depths of wire arrays. These results illustrate that microwire array not only delivers reducing equivalents for $\mathrm{N}_{2}$ fixation, but also creates the hypoxic domains in air as the root nodules do.

\section{Discussion}

Designing wire array electrodes provide a unique and viable approach to program $\mathrm{O}_{2}$ gradient at microscopic length scale with high fidelity. Our reported proof-of-concept demonstrates that the established $\mathrm{O}_{2}$ gradient enabled by micro-structured electrodes allows the production of nitrogen fertilizer by $\mathrm{O}_{2}$-sensitive microbes in air using sustainable electricity (Supplementary Fig. 11), replacing the carbohydrates from natural photosynthesis as the driving force for biological $\mathrm{N}_{2}$ fixation. The observed generation of free ammonia from symbiotic microorganisms driven by electricity, differs from prior result of planktonic species $^{12}$, highlights the unique biocatalytic utilities of symbiotic diazotrophs in the future. Our demonstration also offers the design principle of porous electrodes ${ }^{24}$ (Supplementary Note 7) for future $\mathrm{N}_{2}$-fxing variants that only contains biocompatible earth-abundant materials (Supplementary Note 8), provides lower cost and better scalability with ingenious engineering design, and employs genetically modified microbes with higher intrinsic rates of $\mathrm{N}_{2}$ fixation. In the long run, the concept of biological|inorganic hybrid system will potentially supplement non-legume crops with electricity-generated fertilizers and reduce the reliance on synthetic alternatives.

\begin{abstract}
Methods
Chemicals and materials. The chemicals, unless otherwise specified, were purchased from Sigma-Aldrich and used as received. The ITO-coated glass slides were obtained from SPI supplies. Silicon wafers were purchased from University Wafer. Silver paint was purchased from Ted Pella. Chemical-resistant tapes were purchased from McMaster-Carr. Plastic tubing and fittings were obtained from IDEX Health \& Science. Polystyrene plates were purchased from Evergreen Scale Models. A-B epoxy adhesives were obtained from Amazon.
\end{abstract}

Numeric simulation of $\mathbf{O}_{\mathbf{2}}$ profile. A three-dimensional microkinetic model in aqueous solution was constructed and simulated using COMSOL Multiphysics (Ver. 5.3). The morphology of the simulated electrode is shown in Fig. 1c. A periodic boundary condition was applied in the $x$ and $y$ directions (Fig. 1c). A diffusion-layer model was applied in the simulation ${ }^{39}$. The boundary condition at the diffusion layer is considered constant and equilibrated with external environment.
The periodicity $p$, defined as the distance between two neighboring wires, is a variable used for parametric sweep. The length $(l)$ and diameter $(d)$ of the wire were set to be 50 and $4 \mu \mathrm{m}$, respectively, given practical issues of device fabrication (see Supplementary Note 2). The diffusion layer thickness $d$, defined as the distance from any point on the boundary of diffusion layer to the nearest electrode surface, was set to be $20 \mu \mathrm{m}$. Such a value is determined based on the experimentally determined $\mathrm{O}_{2}$ profile (blue trace in Fig. 2f), which displays a near-linear $\mathrm{O}_{2}$ profile within about $20 \mu \mathrm{m}$ away from the electrode.

A constant electrochemical voltage $E_{\text {appl }}$ was applied on the electrode's surface. The reaction of electrochemical reduction at the electrode's surface proceeds as

$$
\mathrm{O}_{2}+4 \mathrm{H}^{+}+4 \mathrm{e}^{-} \rightarrow 2 \mathrm{H}_{2} \mathrm{O}
$$

Our model was constructed based on the following equations:

Governing differential equations:

$$
\frac{\partial\left[\mathrm{O}_{2}\right]}{\partial t}=D_{\mathrm{O}_{2}} \nabla^{2}\left[\mathrm{O}_{2}\right]=0
$$

Boundary conditions

At the electrode: (concentration-dependent Tafel equation)

$$
i_{\text {loc }}=-i_{0} \frac{\left[\mathrm{O}_{2}\right]}{c_{\mathrm{O}_{2}}} \exp \left(\frac{-\alpha_{\mathrm{c}} F \eta}{\mathrm{RT}}\right) \text { and } J_{\mathrm{O}_{2}}=\frac{i_{\mathrm{loc}}}{4 F}
$$

At the boundary of diffusion layer

$$
\left[\mathrm{O}_{2}\right]=c_{\mathrm{O}_{2}}
$$

At the other boundaries of the periodic unit cell

Periodic boundary conditions

where $i_{\text {loc }}$ is the local current density of oxygen reduction reaction at aiven location on the electrode boundary, $J_{\mathrm{O}_{2}}$, the flux of $\mathrm{O}_{2}$ mass transport at a given location on the electrode boundary, $i_{0}=3.25 \times 10^{-7} \mathrm{~mA} \mathrm{~cm}^{-2}$, the exchange current density, determined by Tafel analysis of electrochemical measurement of Pt-sputtered wire array electrode in bulk medium (Supplementary Note 9 and Supplementary Fig. 12), $\alpha_{\mathrm{c}}=0.5$ the transfer coefficient, $F$ is the Faraday constant, $R$ is the gas constant, $T$ is the temperature, $\left[\mathrm{O}_{2}\right]$ the local $\mathrm{O}_{2}$ concentration, and $c_{\mathrm{O}_{2}}$ the solubility of $\mathrm{O}_{2}$ in water when equilibrated with air. The over potential $\eta$, is the difference between $E_{\text {appl }}$ and the standard redox potential of $\mathrm{O}_{2} / \mathrm{H}_{2} \mathrm{O}, E_{\mathrm{O}_{2} / \mathrm{H}_{2} \mathrm{O}}^{0}$. Due to the high buffer capability of the medium compared to the demand of proton for $\mathrm{O}_{2}$ reduction, the proton concentration is considered constant throughout the system (Supplementary Note 10). Therefore, the proton concentration in the system is assumed to be constant in the simulation. Additional discussion on the choice of the model can be found in Supplementary Note 11. The values of parameters used for simulation are listed in Supplementary Table 2.

Preparation procedure of microwire array electrode. Si wire array was prepared using photolithography followed by reactive ion etching ${ }^{28} .500 \mu \mathrm{m}$-thick, $4^{\prime} \mathrm{Si}$ wafer (p-type, boron-doped, $\langle 100\rangle$ facet-oriented, $1-10 \Omega \mathrm{cm}^{-1}$, University wafer) was patterned by a contact aligner (Carl Suss MA6) with photoresist (MicroChemicals AZ5214E), and was then developed with MicroChemicals AZ 400K. The microwire array morphology was created by a subsequent reactive ion etching (Unaxis Versaline, FDSE III). A layer of protective silicon dioxide layer on the surface of wire array was created by thermal annealing in air at $1050{ }^{\circ} \mathrm{C}$ for $9 \mathrm{~h}$ in a tube furnace (Lindberg/Blue M, Fisher Scientific). A conformal layer of ITO with 200 -nm thickness was coated via reactive sputtering using ULVAC RF sputtering system. Pt particles of $2 \mathrm{~nm}$ thickness was deposited on the wire's surface with a Anatech Hummer 6.2 sputtering system. The morphology of prepared wire array was characterized by a SEM (JEOL JSM-6700F) equipped with energy dispersive $\mathrm{X}$-ray spectroscopy (EDS, Ametek).

Electrochemical measurement in bulk solution. LSV of the wire-array (Supplementary Fig. 3) in bulk minimal medium was obtained using a typical threeelectrode set-up on Gamry 1010B potentiostat system. The wire array was used as working electrode, a piece of silver paint-coated ITO glass was used as reference electrode, same as the pseudo-reference electrode used in the electrochemical chamber. Pt wire was used as counter electrode. Air/argon-saturated minimal medium was prepared by bubbling air/argon in minimal medium for $30 \mathrm{~min}$. Such minimal medium was used as electrolyte. The LSV was obtained by scanning from 1.0 to $-0.5 \mathrm{~V}$ vs. RHE at the speed of $5 \mathrm{mV} \mathrm{s}^{-1}$.

Construction of electrochemical setup on confocal microscope. An electrochemical setup under a confocal microscope was constructed for both the experimental validation of $\mathrm{O}_{2}$ gradient and the characterization of electricitydriven $\mathrm{N}_{2}$ fixation (Supplementary Fig. 4). A three-electrode electrochemical configuration was fitted into a flow chamber with a chamber thickness of $200 \mu \mathrm{m}$ (Fig. 2b and Supplementary Fig. 4). The wire array electrode constitutes the working electrode. An ITO-coated glass coverslip (\#1.5, $40 \mathrm{~mm} \times 22 \mathrm{~mm}$, SPI supplies), wet etched with $6 \mathrm{M} \mathrm{HCl}$ into two isolated electrodes, was used as the top cover of the chamber. One section of the ITO was sputtered with 7-nm Pt and used 
as the counter electrode; the other one, coated with silver paint (Ted Pella, Inc) at the downstream direction, was designated as the Ag pseudo-reference electrode. Prior to experiment, the Ag pseudo-reference electrode was calibrated in the ZoBell's solution (see method below). The pseudo-references maintain a stable $0.31-0.32 \mathrm{~V}$ vs. standard hydrogen electrode (SHE) throughout the $120 \mathrm{~h}$ of electrochemical operation. A syringe or peristaltic pump was employed to feed the liquid medium into the chamber at a fixed flow rate. A Gamry Interface 1010B was applied for electrochemical characterization. The whole setup is optically transparent and mounted to an inverted laser confocal microscope (Leica SP8 SMD), allowing the use of objectives with working distance of $680 \mu \mathrm{m}$.

Characterization of the $\mathbf{A g}$ pseudo-reference. To characterize the electrode potential vs. SHE, and test the stability of pseudo-reference electrodes, prepared by Ag paste, cyclic voltammetry was conducted in a standard ZoBell's solution ${ }^{40}$ using our Ag pseudo-reference before and after a 120-h operation as reference electrode. In each experiment of cyclic voltammetry, the device is exposed to ZoBell's solution, which is composed of $3.3 \mathrm{mM} \mathrm{K}_{3} \mathrm{Fe}(\mathrm{CN})_{6}, 3.3 \mathrm{mM} \mathrm{K}_{4} \mathrm{Fe}(\mathrm{CN})_{6}$, and $0.1 \mathrm{M}$ $\mathrm{KCl}^{41}$. Cyclic voltammogram was recorded at a scan rate of $20 \mathrm{mV} \mathrm{s}^{-1}$ using the pseudo-reference electrode as the reference, a $3.2 \mathrm{~mm}$-diameter glassy carbon electrode as working electrode, and a Pt wire as the counter electrode (Supplementary Fig. 13). A minimal amount of time for the exposure of ZoBell's solution was ensured so that the exposure per se will not alter the redox potential of the pseudo-reference electrodes. As the ZoBell's solution is known to have a redox potential of $+0.43 \mathrm{~V}$ vs. SHE ${ }^{41}$, the potentials of pseudo-reference electrode were able to be obtained by determining the mid-point potential of $\mathrm{Fe}(\mathrm{III}) / \mathrm{Fe}(\mathrm{II})$ redox couple in the cyclic voltammograms. Representative cyclic voltammograms before (Supplementary Fig. 13, black line, mid-point potential $=113 \mathrm{mV}$ vs. reference) and after (Supplementary Fig. 13, red line, mid-point potential $=117 \mathrm{mV}$ vs. reference) 120 -h operation display minimal differences in the mid-point potential of $\mathrm{Fe}(\mathrm{III}) / \mathrm{Fe}(\mathrm{II})$ redox couple, illustrating that the pseudo-reference electrodes maintain a stable $0.31-0.32 \mathrm{~V}$ vs. SHE over an extended period of time.

Experimental validation of $\mathbf{O}_{\mathbf{2}}$ gradients. In situ phosphorescence and lifetime imaging of $\mathrm{Ru}(\mathrm{phen})_{3} \mathrm{Cl}_{2}$ was employed in the microwire electrode to validate the proposed $\mathrm{O}_{2}$ gradients (Fig. 2b). The phosphorescence was monitored at $570-650 \mathrm{~nm}$ by a $470-\mathrm{nm}$ laser excitation, with a $\times 20$ immersion type objective lens (Leica $\times 20$ HC PL APO IMM CS2 NA/0.75). $0.1 \mathrm{mM} \mathrm{Ru(phen)})_{3} \mathrm{Cl}_{2}$ (SigmaAldrich) in $1 \times$ phosphate buffered saline (PBS, $\mathrm{pH}=7.0$, Supplementary Table 3 ) was being flowed through the chamber with a syringe pump (New Era Pump Systems, Inc.) at a flow rate of $2 \mathrm{~mL} \mathrm{~min}-1$.

The intensity of phosphorescence emission was collected by photon multiplier tube detectors (PMT). The data was acquired using Leica Application Suite X (LASX) on $x-z-t$ mode at a spatial resolution of $146 \mathrm{~nm} /$ pixel, taking $x-z$ crosssectional images at the speed of $2.773 \mathrm{~s}$ per frame (Fig. $2 \mathrm{c}, \mathrm{d}$ ). The absolute phosphorescent intensity is lower at the region near the bottom of the wire array as shown in Fig. 2c, d, which indicate the intensity $I_{\mathrm{em}}$ fluorescent emission is prone to possible interference from the optical absorption of $\mathrm{Si}$ wire array, as the $\mathrm{Si}$ wire array can absorb some of the incident and emitted photons. Therefore, the quantitative analysis of local $\mathrm{O}_{2}$ concentration was conducted by PLIM, in which the lifetime measurement is independent of light intensity. The spatially resolved lifetime measured was conducted using time-correlated single photon counting module (HydraHarp, PicoQuant) integrated to the microscope. A 470-nm pulsed laser was used as excitation light and the emitted photon between 570 and $650 \mathrm{~nm}$ were collected using Leica hybrid detector (HyD) coupled with the TCSPC module. The spatial lifetime information was processed by the fluorescent lifetime imaging software Symphotime (PicoQuant). Single exponential tail fitting was used to analyze phosphorescent decay and calculate lifetime. Our measurements were calibrated against standard solutions of known $\mathrm{O}_{2}$ concentration without applied electric potential. A linear fit between the reciprocal lifetime $\tau^{-1}$ against $\left[\mathrm{O}_{2}\right]$ (Supplementary Fig. 6) suggests high fidelity of the method to quantify $\mathrm{O}_{2}$ concentrations. Due to the laminar flow pattern within the flow cell, the generated $\mathrm{O}_{2}$ near the counter electrode (Supplementary Fig. 14) does not affect the $\mathrm{O}_{2}$ gradient near the wire array (Supplementary Note 12). Results measured in PBS is representative for results measured in microbial medium used for $\mathrm{N}_{2}$ fixation experiments, as the quantification method is proven not sensitive to the composition of medium (Supplementary Note 13 and Supplementary Fig. 15). Detailed technical parameters for imaging process can be found in Supplementary Methods.

Bacterial strains and culturing methods. $X$. autotrophicus (X. autotrophicus, ATCC 35674) was purchased from American Type Culture Collection (ATCC), $B$. japonicum (USDA DES 122, DSM 1755) was purchased from German Collection of Microorganisms and Cell Cultures (DSMZ), and B. japonicum-H1 (B. japonicum-H1) ${ }^{34}$ was courtesy of Prof. Ann Hirsch. Microbes were cultured using the following procedure ${ }^{5,13}$. Bacterial samples were thawed from frozen stock (Supplementary Methods) and incubated aerobically in succinate nutrient broth (Supplementary Table 4 ) at $30^{\circ} \mathrm{C}$ for overnight, reaching an optical density of $600 \mathrm{~nm}\left(\mathrm{OD}_{600}\right)$ higher than 1 . The cultured cells were harvested by centrifugation and re-suspended at an initial $\mathrm{OD}_{600}=0.25$ in a $\mathrm{pH}=7.0$ liquid medium deprived of any nitrogen and organic carbon sources, whose recipes are available in Supplementary Tables 5 and 6 for X. autotrophicus and B. japonicum, respectively. The cultures were incubated under a hypoxic condition $\left(3 \% \mathrm{O}_{2}, 20 \% \mathrm{H}_{2}, 17 \% \mathrm{CO}_{2}, 60 \%\right.$ $\mathrm{N}_{2}$ ) at $30^{\circ} \mathrm{C}$ for 6 days in a sealed jar (Vacu-Quik Jar, Almore). The resultant $\mathrm{OD}_{600}$ after 6 days were about 0.7-1.0. As the B. japonicum-H1 strain is incapable to fix $\mathrm{N}_{2}$, the microbial growth medium was supplemented with $\left(\mathrm{NH}_{4}\right)_{2} \mathrm{SO}_{4}$ at a concentration of $1.25 \mathrm{~g} \mathrm{~L}^{-1}$ and cultured for 6 days in a gas environment with $10 \%$ $\mathrm{O}_{2}, 40 \% \mathrm{H}_{2}, 10 \% \mathrm{CO}_{2}$, and $40 \% \mathrm{~N}_{2}$.

Electricity-powered biological|inorganic $\mathbf{N}_{\mathbf{2}}$ fixation. Diazotroph cultures $\left(\mathrm{OD}_{600}=1.0\right)$, starved at room temperature for $6 \mathrm{~h}$, were introduced into the electrochemical chamber equipped with microwire array, which was sterilized by isopropyl alcohol before use. The microbes were allowed to associate with the wire array for one hour, before the chamber were rinsed with cell-free medium to remove excessive planktonic cells. The association was probably due to the adhesion between microbes and wire array (Supplementary Note 14). The medium utilized here was pre-equilibrated with air before injection and deprived of any nitrogen and organic carbon sources, so that any observable biomass accumulation is a result of $\mathrm{N}_{2}$ and $\mathrm{CO}_{2}$ fixation. After the inoculation procedure, an electrochemical bias $\left(E_{\text {appl }}\right)$ was applied to the electrochemical setup while a culture medium, presaturated with air, was flown through the chamber at a flow rate of $2 \mathrm{~mL} \mathrm{~min}^{-1}$. A typical experiment was conducted for at least $120 \mathrm{~h}$ at $30^{\circ} \mathrm{C}$. The current densities during the experiments were recorded (Supplementary Fig. 16). Biofilm formation was not found during the period of 120 -h incubation (Supplementary Note 15).

The microbial culture within the wire array was characterized by a variety of methods. Fluorescence imaging was employed to monitor the microbial population, by staining the microbes with a 1x PBS solution of $10 \mu \mathrm{M}$ Rhodamine 6G (Alfa Aesar) solution for $15 \mathrm{~min}$ before flushed out. Fluorescence emission at $570-650 \mathrm{~nm}$ was collected with the use of a $532-\mathrm{nm}$ laser excitation. The images were taken on $x-y-z$ mode, taking $x-y$ cross-sectional image on different $z$-axis position at a spatial resolution of $146 \mathrm{~nm} /$ pixel with a $z$ increment of $1 \mu \mathrm{m}$. Such a fluorescence characterization leads to the determination the changes of microbial cell counts $(\triangle \mathrm{CC})$ in the wire array. Colorimetric assays that were used in environmental monitoring ${ }^{42,43}$ were employed to yield the changes of total nitrogen content $(\Delta \mathrm{TN})$ and the changes of total organic carbon $(\Delta \mathrm{TOC})$.

Estimation of bacterial growth within the wire array. We estimated the number of bacteria within the wire array using phosphorescence image obtained from confocal microscopy. For each $x-y$ cross-sectional image, we estimate the total cell number by the total pixel number considered "light", judged by a certain intensity threshold. The fluorescent image was processed using ImageJ. White noise was removed using "remove outliers" command under the settings of 2.0 pixels radius and 30 as outlier threshold. The image was then transformed into a binary figure with the intensity threshold, in which "light" pixels are "1"s and "dark" pixels are " 0 "s. The sum of all "light" pixels in an image reveals how many pixels are representing stained bacterial cells. The higher the sum, the more cells are in the image, as displayed in Fig. 3e. To quantify the absolute cell number, we used external standard. Briefly, a "standard image" was captured, using the same method and scan resolution as used in our microscopic observations, on a single-layered bacterial sample with each bacterium separated from each other. The total cell number in the image was manually counted, and the sum of "light" pixels was calculated after the same image-processing method mentioned above. The average pixel number per bacteria (pix/bacteria) was then obtained. For each $x-y$ cross-sectional image, the sum of "light" pixels is divided by pix/bacteria to calculate the total number of bacteria in one image. This may lead to slight underestimation of bacterial numbers, due to the assumption that there was no overlap between bacteria in our captured images. To estimate the overall cell number in the three-dimensional space within the wire array, we assume that from the bottom of wire to the top of wire a new batch of bacteria will be observed with every $5 \mu \mathrm{m}$ increase in $z$, as bacteria that were more than $5 \mu \mathrm{m}$ away from focus plane will not appear in the cross-sectional image. Thus the overall number within the observed wire array would be $N_{\text {average }} \times$ $(l / 5 \mu \mathrm{m})$, where $l$ is the length of wire and $N_{\text {average }}$ is the average bacterial number in $x-y$ cross-sectional images acquired at different distances from wire bottom $(z)$. As we noticed the bacterial growth at different $z$ were not equal (as shown in Fig. $3 \mathrm{e}-\mathrm{g}$ ), the average cell number $N_{\text {average }}$ was taken by averaging the cell number in $x-y$ images at $z=0,10,20,30,40$, and $50 \mu \mathrm{m}$ for a $l=50 \mu \mathrm{m}$ wire array. The cell number in terms of density was acquired by dividing the overall cell number by the volume of imaged space. The increase in cell number was calculated by the difference of cell number after 5 days incubation and the cell number right after inoculation.

Total nitrogen (TN) and organic carbon determination. The general method to determine TN and total organic carbon (TOC) retained in biomass within wire array is multiplying the TN and TOC of a single bacterium by the number density of bacteria within the wire array, which is determined using method described in the method above. First, TN and TOC of bacterial culture with known cell number are determined by absorbance spectrometry using test kits (Hach, kit \#10071 for TN 
and Hach, kit \#10627 for organic carbon). 5-day lithotrophically cultured bacterial cells are harvested from culture using centrifugation and re-suspended in nitrogen and organic carbon-free medium. The $\mathrm{OD}_{600}$ of bacteria suspension was adjusted to 0.7 before testing. The measuring procedure is briefly described here. For TN quantification, $2 \mathrm{~mL}$ of bacterial suspension is first digested using alkaline persulfate solution. This step quantitatively transforms all nitrogen species into nitride. Then the solution was acidified to so that all nitrides turns to nitric acid. The nitric acid was then reacted with phenol, as this quantitative reaction yields yellow colored benzoquinone. The absorbance of generated benzoquinone at $410 \mathrm{~nm}$ is thus dependent on the concentration of nitric acid, which relates to the TN amount in bacteria. A calibration curve correlating the absorbance at $410 \mathrm{~nm}$ and TN concentration (Supplementary Fig. 17) was constructed using the kit on different standard nitrogen sample solutions (ammonium $p$-toluenesulfonate, Hach). For TOC quantification, $2 \mathrm{~mL}$ of bacterial suspension was first acidified and heated to remove inorganic carbonates. Then the solution was digested using persulfate to oxidize all organic carbon into carbon dioxide. The generated carbon dioxide was quantitatively absorbed using acid-base indicator solution. The carbonic acid originated from absorbed carbon dioxide will then react with the indicator and yield a product (the conjugated acid of the indicator) that show increase in the absorbance at $435 \mathrm{~nm}$. A calibration curve correlating the absorbance at $435 \mathrm{~nm}$ and TOC concentration (Supplementary Fig. 18) was constructed using the kit on different standard nitrogen sample solutions (TOC standard, $1000 \mathrm{mg} \mathrm{L}^{-1}$, Hach). The absorbance was measured using a Hewlett-Packard 8453 UV-vis spectrometer.

Second, the number density of bacteria per $\mathrm{OD}_{600}$ were $2.8 \times 10^{8} \mathrm{~mL}^{-1}$ for $X$. autotrophicus ${ }^{12}$, and $1.0 \times 10^{9} \mathrm{~mL}^{-1}$ for B. japonicum. The number of $B$. japonicum per $\mathrm{OD}_{600}$ was determined using flow cytometry, which was run on a BD LSRII (IMED) analytic flow cytometer. The values of nitrogen content of each single cell were calculated using the overall $\mathrm{TN}$ or TOC of a culture with certain $\mathrm{OD}_{600}$ divided by the number of bacterium.

The TN and organic carbon for single bacterium cell $(n=3)$ :

\section{Strain}

Total nitrogen ( $\mathrm{mg} \mathrm{cell}^{-1}$ ) Total organic carbon $\left(\mathrm{mg} \mathrm{cell}^{-1}\right)$

$X$. autotrophicus $1.5 \pm 0.0 \times 10^{-10}$

$6.4 \pm 0.3 \times 10^{-10}$

B. japonicum $4.4 \pm 0.3 \times 10^{-11}$

$1.6 \pm 0.0 \times 10^{-10}$

In order to validate the quantification method described above, when necessary, the microfluidic setup was carefully dissembled. The microorganisms in the setup were carefully extracted by rinsing with minimal medium and mechanically scratching microwire array electrodes. As the microwire array electrodes were made of $\mathrm{Si}, \mathrm{SiO}_{2}$, indium tin oxide (ITO), and $\mathrm{Pt}$, the mechanically detached particles of wire array will not interfere with the oxidative procedure for the measurement of TN in the microorganisms. Similar methods as mentioned above was applied on the detached microbes. The overall microbial nitrogen, after $120 \mathrm{~h}$ under $E_{\text {apple }}=-0.15 \mathrm{~V}$ vs. RHE in $p=15 \mu \mathrm{m}$ microwire array, were $2.48 \pm 0.52$ and $0.503 \pm 0.077 \mu \mathrm{g}$ for $X$. autotrophicus and B. japonicum, respectively $(n=2)$, which corresponds to 992 and $201 \mathrm{mg} \mathrm{L}^{-1}$ within the wire array for $X$. autotrophicus and B. japonicum, respectively. These values are very close to the values measured using the general method mentioned above $\left(975\right.$ and $196 \mathrm{mg} \mathrm{L}^{-1}$ $\mathrm{N}$ for $X$. autotrophicus and B. japonicum, respectively), validating our method of nitrogen quantification mentioned above.

The amount of free ammonia in the effluent of our $\mathrm{N}_{2}$ fixation system is also determined by absorbance spectrometry using test kit (Hach, TNTplus 830). The flow cell with $p=15 \mu \mathrm{m}$ microwire array is inoculated with bacteria and run under $E_{\text {apple }}=-0.15 \mathrm{~V}$ vs. RHE for $120 \mathrm{~h}$, same as described in methods. The flow speed was $2 \mathrm{~mL} \mathrm{~min}^{-1}$. A total of $20 \mathrm{~mL}$ of medium was used and the effluent was circulated in the system to accumulate released ammonia to a detectable level. The increase of ammonia nitrogen was determined by absorbance spectrometry (Hach, Method 10205). $5 \mathrm{~mL}$ of effluent was added into the reaction mixture of the kit. After thoroughly mixing, the mixture was reacted for $15 \mathrm{~min}$. The final solution's absorbance at $694 \mathrm{~nm}$ was used to determine the amount of ammonia. The increase of ammonia nitrogen was found to be $0.017 \pm 0.003 \mathrm{mg} \mathrm{L}^{-1}$ in the effluent of $B$. japonicum $(n=2)$. In the effluent of X. autotrophicus, we did not find detectable amount of ammonia. Therefore, it is considered as $0 \mathrm{mg} \mathrm{L}^{-1}$ in our calculations for activities and efficiencies. Comparing with the value of $187 \mathrm{mg} \mathrm{L}^{-1}$ (B. japonicum) for the increased biomass nitrogen under the same condition, the free ammonia accounts for more than $40 \%$ of the $\mathrm{TN}$ fixed by B. japonicum.

$\mathbf{N}_{\mathbf{2}}$ fixation activity calculation. The activity of $\mathrm{N}_{2}$ fixation displayed in Supplementary Table 1 is calculated in two units: $\mathrm{mg} \mathrm{N}_{2}$ per liter per hour $\left(r N_{\mathrm{V}}\right)$ and $\mathrm{mg}$ $\mathrm{N}_{2}$ per g dry weight biomass per hour $\left(r N_{\mathrm{m}}\right)$. The experimental results for microbes cultured using $p=15 \mu \mathrm{m}$ microwire array under $E_{\text {apple }}=-0.15 \mathrm{~V}$ vs. RHE for $120 \mathrm{~h}$ (Fig. 3d, entries 1 and 2) are used.

$r N_{\mathrm{V}}$ was calculated by the volumetric increase of total nitrogen $(\Delta \mathrm{TN})$ in biomass and free ammonia released in medium:

$$
r N_{\mathrm{V}}=\frac{\Delta \mathrm{TN}_{\text {bio }} \times V_{\text {wire array }}+\Delta \mathrm{TN}_{\text {medium }} \times V_{\text {medium }}}{V_{\text {wire array }} \times t}
$$

where $\Delta \mathrm{TN}_{\text {bio }}$ is the increase of $\mathrm{TN}$ in microbe cells within the array $\left(5.7 \times 10^{2}\right.$ and $1.9 \times 10^{2} \mathrm{mg} \mathrm{L}^{-1}$ for $X$. autotrophicus and B. japonicum, respectively), $V_{\text {wire array }}$ the volume of wire array $\left(2.5 \times 10^{-6} \mathrm{~L}\right), \Delta \mathrm{TN}_{\text {medium }}$ the increase of $\mathrm{TN}$ as ammonia in microbial growth medium $\left(0 \mathrm{mg} \mathrm{L}^{-1}\right.$ for X. autotrophicus and $0.017 \mathrm{mg} \mathrm{L}^{-1}$ for B. japonicum), $V_{\text {medium }}$ the volume of medium circulated in the device during operation $(20 \mathrm{~mL}), t$ the overall incubation time $(120 \mathrm{~h})$. From the equation we calculate the $r N_{V}$ values, which are 4.8 and $2.7 \mathrm{mg} \mathrm{L}^{-1} \mathrm{~h}^{-1}$ for X. autotrophicus and B. japonicum, respectively.

$r N_{\mathrm{m}}$ was calculated using the sum of $\Delta \mathrm{TN}$ and free nitrogen in effluent divided by the bacterial average dry mass $\left(\mathrm{TN}_{\text {average }} / 15 \%\right)$ :

$$
r N_{\mathrm{m}}=\frac{\Delta \mathrm{TN}_{\text {bio }} \times V_{\text {wire array }}+\Delta \mathrm{TN}_{\text {medium }} \times V_{\text {medium }}}{\mathrm{TN}_{\text {average }} \times V_{\text {wire array }} \times t / 15 \%} \times 1000
$$

under the assumption that nitrogen constitutes $15 \%$ of bacterial dry mass. $\mathrm{TN}_{\text {average }}$ is the average nitrogen content in microbes over the growth time. We assume exponential growth and take the average of the biomass amount throughout the 120 - $\mathrm{h}$ incubation as the $\mathrm{TN}_{\text {average }}\left(644\right.$ and $61 \mathrm{mg} \mathrm{L}^{-1}$ for $X$. autotrophicus and B. japonicum, respectively). $\Delta \mathrm{TN}_{\mathrm{bio}}$ is the increase of $\mathrm{TN}$ in microbe cells within the array $\left(5.7 \times 10^{2}\right.$ and $1.9 \times 10^{2} \mathrm{mg} \mathrm{L}^{-1}$ for $X$. autotrophicus and B. japonicum, respectively), $V_{\text {wire array }}$ the volume of wire array $\left(2.5 \times 10^{-6} \mathrm{~L}\right), \Delta \mathrm{TN}_{\text {medium }}$ the increase of TN as ammonia in microbial growth medium $\left(0 \mathrm{mg} \mathrm{L}^{-1}\right.$ for $X$. autotrophicus and $0.017 \mathrm{mg} \mathrm{L}^{-1}$ for $B$. japonicum), $V_{\text {medium }}$ the volume of medium circulated in the device during operation $(20 \mathrm{~mL}), t$ the overall incubation time $(120 \mathrm{~h})$. The values of TN of inoculum. The $r N_{\mathrm{m}}$ values are 1.1 and $6.5 \mathrm{mg} \mathrm{g}^{-1} \mathrm{~h}^{-1}$ for X. autotrophicus and B. japonicum, respectively.

Calculation of Faradaic efficiency (FE) and energy cost. We define FE as the percentage of electron that has been used to reduce $\mathrm{N}_{2}$ and $\mathrm{CO}_{2}$ to form microbial biomass and secreted ammonia. The FE is calculated as follows:

$$
\mathrm{FE}=\frac{F\left[3 \frac{\Delta \mathrm{TN}_{\text {bio }} \times V_{\text {wirearay }}+\Delta \mathrm{TN}_{\text {medium }} \times V_{\text {medium }}}{M_{\mathrm{N}}}+4 \frac{\Delta \mathrm{TOC}_{\text {bio }} \times V_{\text {wirearay }}}{M_{\mathrm{C}}}\right]}{i \times A \times t} \times 100 \%
$$

where $\Delta \mathrm{TN}_{\text {bio }}$ is the increase of $\mathrm{TN}$ in microbe cells within the array $\left(5.7 \times 10^{2}\right.$ and $1.9 \times 10^{2} \mathrm{mg} \mathrm{L}^{-1}$ for $X$. autotrophicus and B. japonicum, respectively), $V_{\text {wire array }}$ the volume of wire array $\left(2.5 \times 10^{-6} \mathrm{~L}\right), \Delta \mathrm{TN}_{\text {medium }}$ the increase of $\mathrm{TN}$ as ammonia in microbial growth medium $\left(0 \mathrm{mg} \mathrm{L}^{-1}\right.$ for X. autotrophicus and $0.017 \mathrm{mg} \mathrm{L}^{-1}$ for $B$. japonicum), $V_{\text {medium }}$ the volume of medium circulated in the device during operation $(20 \mathrm{~mL}), \triangle \mathrm{TOC}_{\text {bio }}$ the increase of TOC in microbe cells within the array $\left(2.5 \times 10^{3}\right.$ and $6.9 \times 10^{2} \mathrm{mg} \mathrm{L}^{-1}$ for $X$. autotrophicus and B. japonicum, respectively), $i$, the overall current density that pass through the wire array electrode during the $120 \mathrm{~h}$ operation of our hybrid system (ca. $80 \mu \mathrm{A} \mathrm{cm}-2$ ), $A$, the projected area of wire array electrode $\left(0.5 \mathrm{~cm}^{2}\right), t$ the overall operation time $(120 \mathrm{~h}$, correspondingly $432,000 \mathrm{~s}), F$, Faraday constant $\left(96,485 \mathrm{C} \mathrm{mol}^{-1}\right), M_{\mathrm{N}}$ and $M_{\mathrm{C}}$ the molar atomic weight of $\mathrm{N}\left(14 \mathrm{~g} \mathrm{~mol}^{-1}\right)$ and $\mathrm{C}\left(12 \mathrm{~g} \mathrm{~mol}^{-1}\right)$, respectively. The FEs are calculated to be $1.4 \%$ and $0.42 \%$ for X. autotrophicus and B. japonicum, respectively ( $p=15 \mu \mathrm{m} ; E_{\text {appl }}=-0.15 \mathrm{~V}$ vs. RHE).

The energy cost of nitrogen fixation in terms of $\mathrm{kJ} / \mathrm{g}$ nitrogen is estimated using the following equation:

$$
E_{\mathrm{N}}=\frac{i \times t \times A \times U}{1000 \times\left(\Delta \mathrm{TN}_{\text {bio }} \times V_{\text {wire array }}+\Delta \mathrm{TN}_{\text {medium }} \times V_{\text {medium }}\right)}
$$

where $E_{\mathrm{N}}$ is the energy cost (kJ/g nitrogen), $i$ the current density (ca. $80 \mu \mathrm{A} \mathrm{cm}{ }^{-2}$ ), $A$, the projected area of wire array electrode $\left(0.5 \mathrm{~cm}^{2}\right), t$ the total incubation time with applied voltage ( $120 \mathrm{~h}$, correspondingly $432,000 \mathrm{~s}), U$ the applied potential between the working and the counter electrodes, here we assume $U=1.23 \mathrm{~V}$ for water splitting, $\Delta \mathrm{TN}_{\text {bio }}$ is the increase of $\mathrm{TN}$ in microbe cells within the array $\left(5.7 \times 10^{2}\right.$ and $1.9 \times 10^{2} \mathrm{mg} \mathrm{L}^{-1}$ for $X$. autotrophicus and B. japonicum, respectively), $V_{\text {wire array }}$ the volume of wire array $\left(2.5 \times 10^{-6} \mathrm{~L}\right), \Delta \mathrm{TN}_{\text {medium }}$ the increase of TN as ammonia in microbial growth medium $\left(0 \mathrm{mg} \mathrm{L}^{-1}\right.$ for $X$. autotrophicus and $0.017 \mathrm{mg} \mathrm{L}^{-1}$ for B. japonicum), $V_{\text {medium }}$ the volume of culture medium circulated in the device during operation $(20 \mathrm{~mL})$. Here we consider the nitrogen contents retained in biomass and secreted into the circulating medium. Following the procedure described above, the overall energy cost is $1.5 \times 10^{4}$ and $2.6 \times 10^{4} \mathrm{~kJ} / \mathrm{g}$ nitrogen for $X$. autotrophicus and $B$. japonicum strains, respectively $\left(p=15 \mu \mathrm{m} ; E_{\mathrm{appl}}=-0.15 \mathrm{~V}\right.$ vs. RHE$)$.

\section{Data availability}

The datasets generated or analyzed during the current study are available from the corresponding author upon reasonable request. The source data underlying Figs. 1d, 2e, 2f, 3d, and 3e, and Supplementary Figs. 2, 3, 6, 9, 10, 12, 13, 15-18 are provided as Source Data file, which can be found following the url: https://doi.org/10.6084/m9. figshare.11879715.v2.

\section{Code availability}

The code used in the current study are available from the corresponding author upon reasonable request. 
Received: 17 September 2019; Accepted: 2 March 2020;

Published online: 20 March 2020

\section{References}

1. Fields, S. Global nitrogen: cycling out of control. Environ. Health Perspect. 112, A556-A563 (2004).

2. Mus, F. et al. Symbiotic nitrogen fixation and the challenges to its extension to nonlegumes. Appl. Environ. Microb. 82, 3698-3710 (2016).

3. Wang, D., Yang, S., Tang, F. \& Zhu, H. Symbiosis specificity in the legume-rhizobial mutualism. Cell. Microbiol. 14, 334-342 (2012).

4. Lodwig, E. M. et al. Amino-acid cycling drives nitrogen fixation in the legume-rhizobium symbiosis. Nature 422, 722-726 (2003).

5. Malik, K. A. \& Schlegel, H. G. Chemolithoautotrophic growth of bacteria able to grow under $\mathrm{N}_{2}$-fixing conditions. FEMS Microbiol. Lett. 11, 63-67 (1981).

6. Burns, R. C. \& Hardy, R. W. F. in Nitrogen Fixation in Bacteria and Higher Plants, Vol. 21 in Molecular Biology, Biochemistry and Biophysics (ed. Solioz, M.) 14-38 (Springer-Verlag, Berlin, Heidelberg, 1975).

7. Liu, C., Colón, B. C., Ziesack, M., Silver, P. A. \& Nocera, D. G. Water splittingbiosynthetic system with $\mathrm{CO}_{2}$ reduction efficiencies exceeding photosynthesis. Science 352, 1210-1213 (2016).

8. Sakimoto, K. K., Wong, A. B. \& Yang, P. Self-photosensitization of nonphotosynthetic bacteria for solar-to-chemical production. Science $\mathbf{3 5 1}$ 74-77 (2016)

9. Sakimoto, K. K. et al. Physical biology of the materials-microorganism interface. J. Am. Chem. Soc. 140, 1978-1985 (2018).

10. Guo, J. et al. Light-driven fine chemical production in yeast biohybrids. Science 362, 813-816 (2018).

11. Rodrigues, R. M. et al. Perfluorocarbon nanoemulsion promotes the delivery of reducing equivalents for electricity-driven microbial $\mathrm{CO}_{2}$ reduction. Nat. Catal. 2, 407-414 (2019).

12. Liu, C., Sakimoto, K. K., Colón, B. C., Silver, P. A. \& Nocera, D. G. Ambient nitrogen reduction cycle using a hybrid inorganic-biological system. Proc. Natl Acad. Sci. USA 114, 6450-6455 (2017).

13. Wiegel, J. in The Prokaryotes, Vol. 5: Proteobacteria: Alpha and Beta Subclasses, 3rd edn, (eds Dworkin, M., Falkow, S., Rosenberg, E., Schleifer, K. \& Stackebrandt, E.) 290-314 (Springer-Verlag, New York, 2006).

14. Goldberg, I., Nadler, V. \& Hochman, A. Mechanism of nitrogenase switch-off by oxygen. J. Bacteriol. 169, 874-879 (1987).

15. Wong, P. P. \& Burris, R. H. Nature of oxygen inhibition of nitrogenase from Azotobacter vinelandii. Proc. Natl Acad. Sci. USA 69, 672-675 (1972).

16. Tjepkema, J. D. \& Cartica, R. J. Diffusion limitation of oxygen-uptake and nitrogenase activity in the root-nodules of Parasponia rigida Merr. and Perry. Plant Physiol. 69, 728-733 (1982).

17. Witty, J. F. \& Minchin, F. R. in Nitrogen Fixation: Achievements and Objectives, (eds Gresshoff, P. M., Roth, L. E., Stacey, G. \& Newton, W. E.) 285-292 (Springer US, New York, 1990).

18. Minchin, F. R. Regulation of oxygen diffusion in legume nodules. Soil Biol. Biochem. 29, 881-888 (1997).

19. Lewis, D. M., Blatchley, M. R., Park, K. M. \& Gerecht, S. O ${ }_{2}$-controllable hydrogels for studying cellular responses to hypoxic gradients in three dimensions in vitro and in vivo. Nat. Protoc. 12, 1620-1638 (2017).

20. Rexius-Hall, M. L., Mauleon, G., Malik, A. B., Rehman, J. \& Eddington, D. T. Microfluidic platform generates oxygen landscapes for localized hypoxic activation. Lab Chip 14, 4688-4695 (2014).

21. Brennan, M. D., Rexius-Hall, M. L., Elgass, L. J. \& Eddington, D. T. Oxygen control with microfluidics. Lab Chip 14, 4305-4318 (2014).

22. Rago, L. et al. Bioelectrochemical Nitrogen fixation (e-BNF): electrostimulation of enriched biofilm communities drives autotrophic nitrogen and carbon fixation. Bioelectrochemistry 125, 105-115 (2019).

23. Liu, C. et al. Nanowire-bacteria hybrids for unassisted solar carbon dioxide fixation to value-added chemicals. Nano Lett. 15, 3634-3639 (2015).

24. Newman, J. S. \& Tobias, C. W. Theoretical analysis of current distribution in porous electrodes. J. Electrochem. Soc. 109, 1183-1191 (1962).

25. Natinsky, B. S., Lu, S., Copeland, E. D., Quintana, J. C. \& Liu, C. Solution catalytic cycle of incompatible steps for ambient air oxidation of methane to methanol. ACS Cent. Sci. 5, 1584-1590 (2019).

26. Xiang, C., Meng, A. C. \& Lewis, N. S. Evaluation and optimization of mass transport of redox species in silicon microwire-array photoelectrodes. Proc. Natl Acad. Sci. USA 109, 15622-15627 (2012).

27. Yoon, Y., Hall, A. S. \& Surendranath, Y. Tuning of silver catalyst mesostructure promotes selective carbon dioxide conversion into fuels. Angew. Chem. Int. Ed. 55, 15282-15286 (2016).

28. Liu, C., Tang, J., Chen, H., Liu, B. \& Yang, P. A fully integrated nanosystem of semiconductor nanowires for direct solar water splitting. Nano Lett. 13, 2989-2992 (2013).
29. Li, M. F. et al. Ultrafine jagged platinum nanowires enable ultrahigh mass activity for the oxygen reduction reaction. Science 354, 1414-1419 (2016).

30. Tian, X. L. et al. Unsupported platinum-based electrocatalysts for oxygen reduction reaction. ACS Energy Lett. 2, 2035-2043 (2017).

31. Huntosova, V. et al. In vivo measurement of tissue oxygenation by timeresolved luminescence spectroscopy: advantageous properties of dichlorotris (1, 10-phenanthroline)-ruthenium(II) hydrate. J. Biomed. Opt. 19, 077004 (2014).

32. Wang, X. \& Wolfbeis, O. S. Optical methods for sensing and imaging oxygen: materials, spectroscopies and applications. Chem. Soc. Rev. 43, 3666-3761 (2014).

33. Sugawara, M. et al. Complete genome sequence of Bradyrhizobium diazoefficiens USDA 122, a nitrogen-fixing soybean symbiont. Genome Announc. 5, e01743-16 (2017).

34. Hahn, M., Meyer, L., Studer, D., Regensburger, B. \& Hennecke, H. Insertion and deletion mutations within the Nif region of Rhizobium japonicum. Plant Mol. Biol. 3, 159-168 (1984).

35. Kim, J. \& Rees, D. C. Nitrogenase and biological nitrogen fixation. Biochemistry 33, 389-397 (1994).

36. Rosendahl, L., Dilworth, M. J. \& Glenn, A. R. Exchange of metabolites across the peribacteroid membrane in pea root nodules. J. Plant Physiol. 139, 635-638 (1992).

37. Day, D. A., Poole, P. S., Tyerman, S. D. \& Rosendahl, L. Ammonia and amino acid transport across symbiotic membranes in nitrogen-fixing legume nodules. Cell. Mol. Life Sci. 58, 61-71 (2001).

38. Sadowsky, M. J., Cregan, P. B. \& Keyser, H. H. Nodulation and nitrogen fixation efficacy of Rhizobium fredii with Phaseolus vulgaris genotypes. Appl. Environ. Microb. 54, 1907-1910 (1988).

39. Bard, A. J. \& Faulkner, L. R. Electrochemical Methods: Fundamentals and Applications, 2nd edn (Wiley, New York, 2000).

40. Zobell, C. E. Studies on redox potential of marine sediments. AAPG Bull. $\mathbf{3 0}$, 477-513 (1946)

41. Nordstrom, D. K. Thermochemical redox equilibria of ZoBell's solution. Geochim. Cosmochim. Acta 41, 1835-1841 (1977).

42. Dubber, D. \& Gray, N. F. Replacement of chemical oxygen demand (COD) with total organic carbon (TOC) for monitoring wastewater treatment performance to minimize disposal of toxic analytical waste. J. Environ. Sci. Health A 45, 1595-1600 (2010).

43. Fraser, L. H., Carty, S. M. \& Steer, D. A test of four plant species to reduce total nitrogen and total phosphorus from soil leachate in subsurface wetland microcosms. Bioresour. Technol. 94, 185-192 (2004).

\section{Acknowledgements}

The authors thank Ann Hirsch for the B. japonicum-H1 strain, Yang Yang for thin-film deposition instrument, Matthew Schibler and Justin Caram for helpful discussions. C.L. acknowledges startup fund and faculty research grant from the University of California, Los Angeles, and the financial support of the Jeffery and Helo Zink Endowed Professional Development Term Chair. Confocal laser scanning microscopy was performed at the Advanced Light Microscopy/Spectroscopy Laboratory and the Leica Microsystems Center of Excellence at the California NanoSystems Institute at UCLA with funding support from NIH Shared Instrumentation Grant S10OD025017 and NSF Major Research Instrumentation grant CHE-0722519.

\section{Author contributions}

S.L. and C.L. conceived the idea and wrote the manuscript together. S.L and X.G. conducted the experiments.

\section{Competing interests}

The authors declare no competing interests.

\section{Additional information}

Supplementary information is available for this paper at https://doi.org/10.1038/s41467 020-15314-9.

Correspondence and requests for materials should be addressed to C.L.

Peer review information Nature Communications thanks Benjamin Korth, Korneel Rabaey and Narcis Pous for their contribution to the peer review of this work.

Reprints and permission information is available at http://www.nature.com/reprints

Publisher's note Springer Nature remains neutral with regard to jurisdictional claims in published maps and institutional affiliations. 
(c) (i) Open Access This article is licensed under a Creative Commons Attribution 4.0 International License, which permits use, sharing, adaptation, distribution and reproduction in any medium or format, as long as you give appropriate credit to the original author(s) and the source, provide a link to the Creative Commons license, and indicate if changes were made. The images or other third party material in this article are included in the article's Creative Commons license, unless indicated otherwise in a credit line to the material. If material is not included in the article's Creative Commons license and your intended use is not permitted by statutory regulation or exceeds the permitted use, you will need to obtain permission directly from the copyright holder. To view a copy of this license, visit http://creativecommons.org/ licenses/by/4.0/.

(C) The Author(s) 2020 